\title{
COMPLEX IMPEDANCE OF MANGANESE FERRITE POWDERS OBTAINED BY TWO DIFFERENT METHODS
}

\author{
I. Mălăescu ${ }^{1}$, Antoanetta Lungu ${ }^{1}$, C. N. Marin ${ }^{1}$, Paulina Vlăzan ${ }^{2}$, Paula Sfirloagă ${ }^{2}$ \\ ${ }^{1}$ West University of Timisoara, Faculty of Physics, Bd.V. Parvan, No. 4, 300223 Timisoara, Romania, \\ ${ }^{2}$ National Institutes for Research and Development in Electrochemistry and Condensed Matter, 300569 Timisoara, \\ Romania
}

Article Info

Received: 23.09.2015

Accepted: 26.11 .2015

Keywords: Manganese ferrite; hydrothermal synthesis; Complex impedance;

\section{Introduction}

Two samples of manganese ferrite powder were obtained by the calcination method (sample A) and hydrothermal method (sample B). The crystal structure of the samples has been determined using X-ray diffraction analysis (XRD). The results shown that the sample A has three phases $\left(\mathrm{FeMnO}, \mathrm{Mn}_{2} \mathrm{O}_{3}\right.$ and $\mathrm{Fe}_{2} \mathrm{O}_{3}$ ) and the prevailing phase is $\mathrm{FeMnO}_{3}$ with perovskite structure and the sample $\mathrm{B}$ has only a single phase $\left(\mathrm{MnFe}_{2} \mathrm{O}_{4}\right)$.

The grain morphology was analyzed by scanning electron microscopy (SEM) and the compositional analysis was done by energy dispersive spectroscopy (EDAX).

Measurements of the frequency $(f)$ and temperature $(T)$ dependent complex impedance, $Z(f, T)=Z^{\prime}(f, T)-i Z^{\prime \prime}(f, T)$ of the samples over the frequency range $20 \mathrm{~Hz}-2 \mathrm{MHz}$, at various temperature values from $30^{\circ} \mathrm{C}$ to $110^{\circ} \mathrm{C}$ are presented. From these measurements, we have shown that the temperature dependence of the relaxation time is of Arhenius type, which suggests that the conduction process is thermally activated. The values obtained for the activation energy $E a$, are: $16 \mathrm{meV}$ (sample A) and $147.65 \mathrm{meV}$ (sample B).

Applying complex impedance spectroscopy technique, the obtained results shows the shape of a single semicircle at each temperature over the measurement range, meaning that the electrical process obeys to a single relaxation mechanism. The impedance and related parameters of the electrical equivalent circuit depend on the temperature and the microstructure of samples. The resistive and capacitive properties of the investigated samples are dominated with the conduction and relaxation processes associated with the grain boundaries mechanism..

Manganese ferrites belong to a group of ferrite characterized by high magnetic permeability and low losses. These materials are extensively used in many applications such as microwave devices, magnetic recording media, radio frequency coil fabrication, transformer 
cores, rod antennas and many branches of telecommunication and electronic engineering [1]. The structural and electric properties of spinel ferrites depend on the method of preparation.

In various studies, manganese ferrite was obtained using $\mathrm{FeSO}_{4} \cdot 7 \mathrm{H}_{2} \mathrm{O}$ and $\mathrm{MnSO}_{4} \cdot \mathrm{H}_{2} \mathrm{O}$ [2] or $\mathrm{Mn}\left(\mathrm{NO}_{3}\right)_{2} \cdot 4 \quad \mathrm{H}_{2} \mathrm{O}$ and $\mathrm{Fe}\left(\mathrm{NO}_{3}\right)_{3} \cdot 9 \quad \mathrm{H}_{2} \mathrm{O}$ [3-4] as reactants, at different calcination temperatures and by mixing with different molar ratios for the same reaction [5].

In this paper using as raw material $\mathrm{MnCl}_{2} \cdot 4 \mathrm{H}_{2} \mathrm{O}$ and $\mathrm{FeCl}_{3} \cdot 6 \mathrm{H}_{2} \mathrm{O}$ two samples of manganese ferrite powder have been prepared using the calcinations and hydrothermal methods. The crystal structure of the samples has been determined using X-ray diffraction. The results have shown that the sample obtained by calcination has perovskite structure and the sample obtained by the hydrothermal method has spinel structure. Powder composition and morphology were analyzed by scanning electron microscopy (SEM) and energy dispersive X-ray spectroscopy (EDX). The electrical properties of the samples were investigated over the frequency range $20 \mathrm{~Hz}-2 \mathrm{MHz}$, at constant temperature values from $30^{\circ} \mathrm{C}$ to $110^{\circ} \mathrm{C}$. For both samples, the complex impedance plane spectra show the presence of only one semicircle at each temperature. The analysis of the data shows that the resistive and capacitive properties of the $\mathrm{Mn}$ ferrite are mainly due to processes associated with grain boundaries of samples.

The obtained results shown that the lattice constants, mass density, X-ray density, electrically properties are affected by the structure.

\section{The obtaining of samples}

The manganese ferrite was prepared via two different methods: sample A was obtained by the calcination method starting from $\mathrm{MnCl}_{2} \cdot 4 \mathrm{H}_{2} \mathrm{O}$ and $\mathrm{FeCl}_{3} \cdot 6 \mathrm{H}_{2} \mathrm{O}$ in molar ratio $\mathrm{Mn}^{2+}: \mathrm{Fe}^{3+}=$ $1: 2$, in addition with urea and ethanol. The ethanol was evaporated by heating and the mixture was then subjected to calcination at $700{ }^{\circ} \mathrm{C}$ for four hours, unlike the reference [3], where the calcination was performed at $900{ }^{\circ} \mathrm{C}$. In Ref. [4], $\mathrm{MnFe}_{2} \mathrm{O}_{4}$ ferrites are synthesized by the lowtemperature combustion method, using $\mathrm{Mn}\left(\mathrm{NO}_{3}\right) 2$ and $\mathrm{Fe}\left(\mathrm{NO}_{3}\right)_{3} \cdot 9 \mathrm{H}_{2} \mathrm{O}$ in addition with citric acid as precursors.

Sample B was obtained by the hydrothermal method which is one of the more successful ways to grow crystals of many different materials [5]. To obtain sample $\mathrm{B}, \mathrm{MnCl}_{2} \cdot 4 \mathrm{H}_{2} \mathrm{O}$ and $\mathrm{FeCl}_{3} \cdot 6 \mathrm{H}_{2} \mathrm{O}$ in aqueous solution were used as raw materials and the precipitation was done with $\mathrm{NaOH}$. The hydrothermal process was realized in a Morey-type autoclave at a temperature of 80 ${ }^{\circ} \mathrm{C}$, for 2 hours. The amounts of precursor materials used for the synthesis of $\mathrm{MnFe}_{2} \mathrm{O}_{4}$ particles 
is indicated in Table 1 and the technological process of obtaining the sample A and B is shown in figure 1a) and figure 1b) respectively.

Table 1. The amounts of precursor materials used for the synthesis of $\mathrm{MnFe}_{2} \mathrm{O}_{4}$ powders

\begin{tabular}{|c|c|c|c|c|}
\hline Sample & $\begin{array}{c}\mathrm{MnCl}_{2} \cdot 4 \mathrm{H}_{2} \mathrm{O} \\
(\mathrm{g})\end{array}$ & $\begin{array}{c}\mathrm{FeCl}_{3} \cdot 6 \mathrm{H}_{2} \mathrm{O} \\
(\mathrm{g})\end{array}$ & $\begin{array}{c}\mathrm{NaOH} 2 \mathrm{M} \\
(\mathrm{ml})\end{array}$ & $\begin{array}{c}\text { urea } \\
(\mathrm{g})\end{array}$ \\
\hline $\mathrm{A}$ & 0,947 & 2,733 & - & 0,61 \\
\hline $\mathrm{B}$ & 0,945 & 2,732 & 15 & - \\
\hline
\end{tabular}

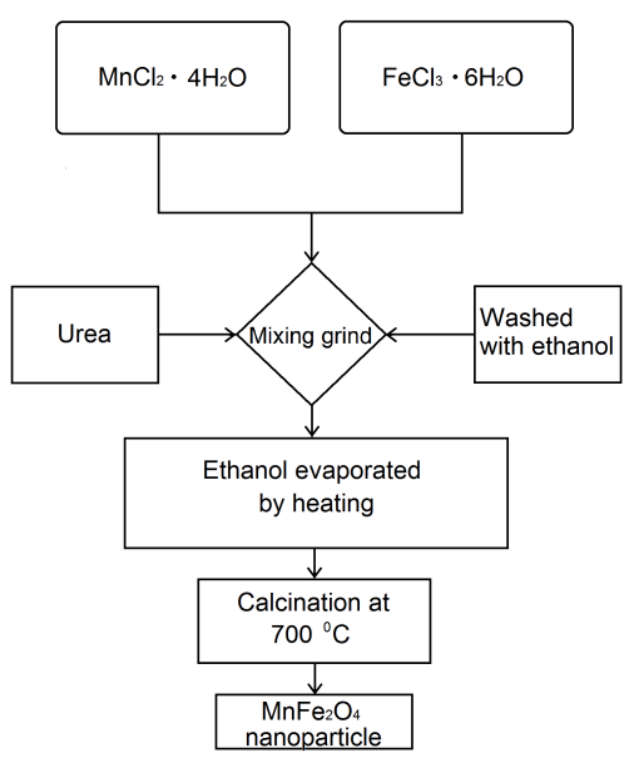

a)

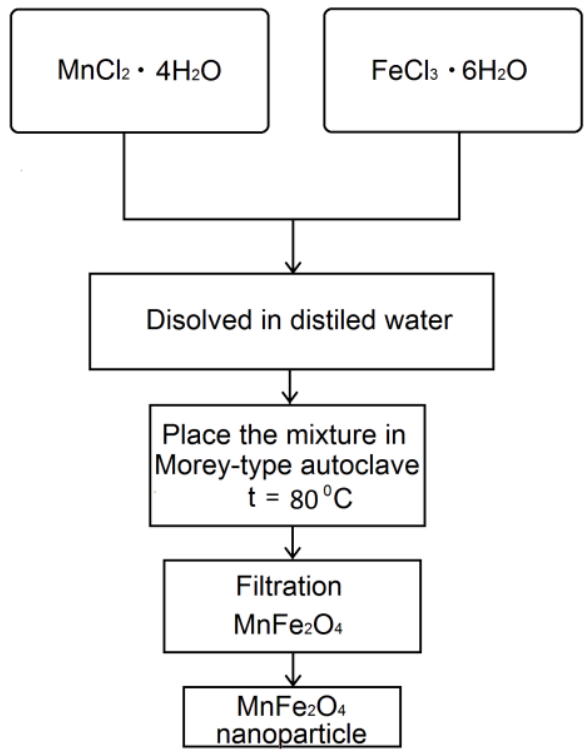

b)

Fig. 1. Flow chart of $\mathrm{MnFe}_{2} \mathrm{O}_{4}$ obtaining methods: the calcination method (a) and the hydrothermal method (b)

\section{Results and Discussions}

\subsection{Structural and morphological analysis}

The structure of the prepared samples was investigated by X-ray diffraction (XRD) using PANalytical X'PertPRO MPD diffractometer.

The XRD patterns of samples $\mathrm{A}$ and $\mathrm{B}$ are illustrated in figure 2. The XRD analysis indicates that sample $A$ exhibits three phases $\left(\mathrm{FeMnO}_{3}, \mathrm{Mn}_{2} \mathrm{O}_{3}\right.$ and $\left.\mathrm{Fe}_{2} \mathrm{O}_{3}\right)$ and the prevailing phase is $\mathrm{FeMnO}_{3}$ with perovskite structure. Also, figure 2 shows that only a single phase of cubic spinel structure (with $F d 3 m$ space group) is obtained by the hydrothermal method (sample B) (JCPDS card No. 75-0034) [6]. 


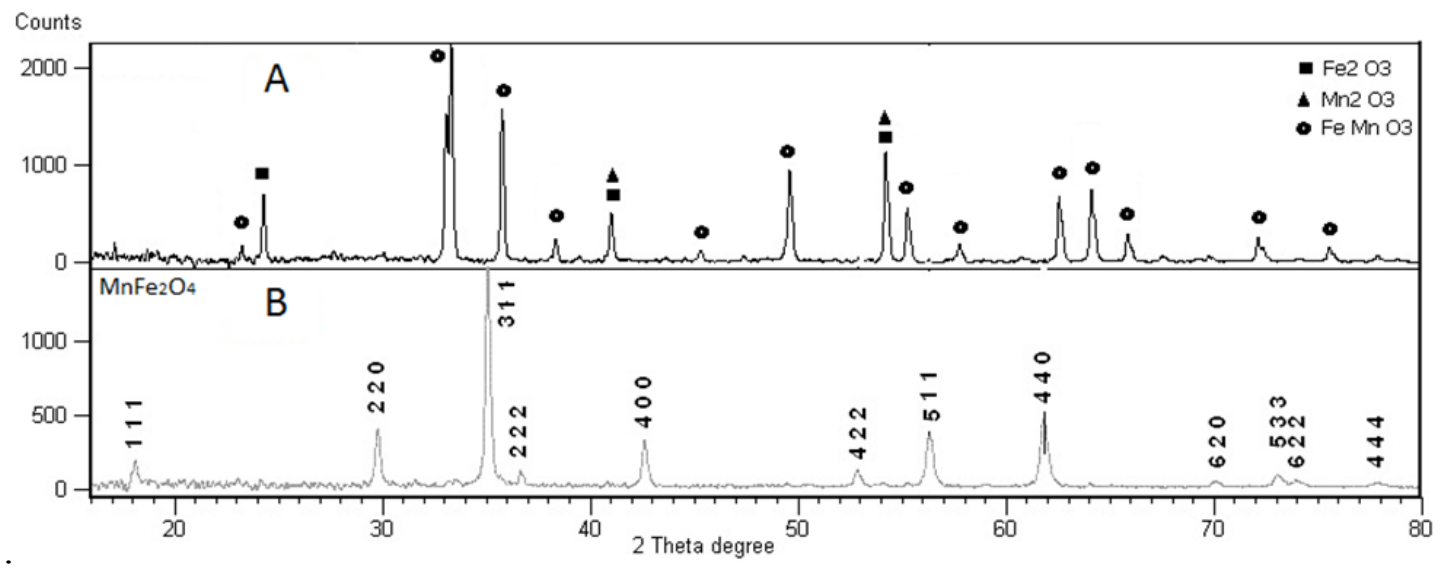

Fig. 2. XRD pattern for sample A and B.

The lattice parameter is calculated according to the formula, $d=\frac{a}{\sqrt{h^{2}+k^{2}+l^{2}}}$ where $a$ is the lattice constant, $d$ the interpleader distance and h, k, 1 are the Miller indices [7]. The theoretical density is computed according to the formula, $d_{x}=\frac{8 M}{N_{a}^{3}}$ where, $\mathrm{M}$ is the molecular mass and $N$ the Avogadro's number. The lattice parameter of both samples and the average crystallite size are presented in table 2.

Table 2. XRD data for sample A and sample B

\begin{tabular}{|l|l|l|}
\hline Sample & $\begin{array}{l}\text { Sample A } \\
\text { Calcination 700 }\end{array}{ }^{\circ} \boldsymbol{C}$ & $\begin{array}{l}\text { Sample B } \\
\text { Hydrothermal }\end{array}$ \\
\hline Substance & $\mathrm{FeMnO}_{3}$ & $\mathrm{MnFe}_{2} \mathrm{O}_{4}$ \\
\hline Crystal system & cubic & cubic \\
\hline Lattice parameter a/ $\AA$ & $9.399(8)$ & $8.4889(8)$ \\
\hline Density $\left(\right.$ calculated $/ \mathrm{g} / \mathrm{cm}^{3}$ & 5.0800 & 5.0077 \\
\hline Weight fraction/ \% & 100.00000 & 100.000000 \\
\hline alpha/ ${ }^{\circ}$ & 90 & 90 \\
\hline V/ $10^{6} \mathrm{pm}^{3}$ & 830.32940 & 611.71610 \\
\hline Crystallite size $(\mathrm{nm})$ & 52.3 & 31.9 \\
\hline
\end{tabular}

Powder morphology was observed using an Inspect S PANalytical model scanning electron microscopy (SEM). The elemental analysis was done with the EDX facility of the scanning electron microscope. Figs. 3 a) and 3 c) show the SEM images of the particles, which are of regular shapes and are aggregated in a spongy structure and in Figs. 3 b) and 3 d), the EDX results are presented. 


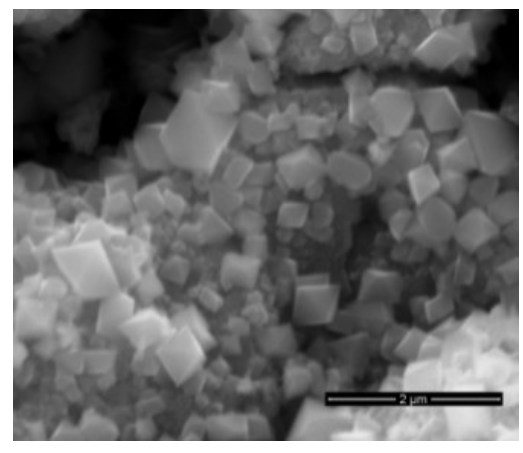

(a)

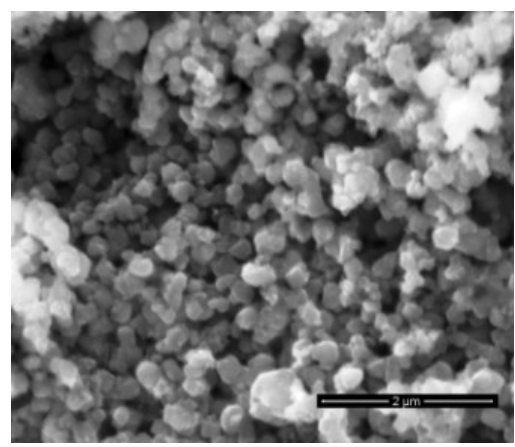

(c)
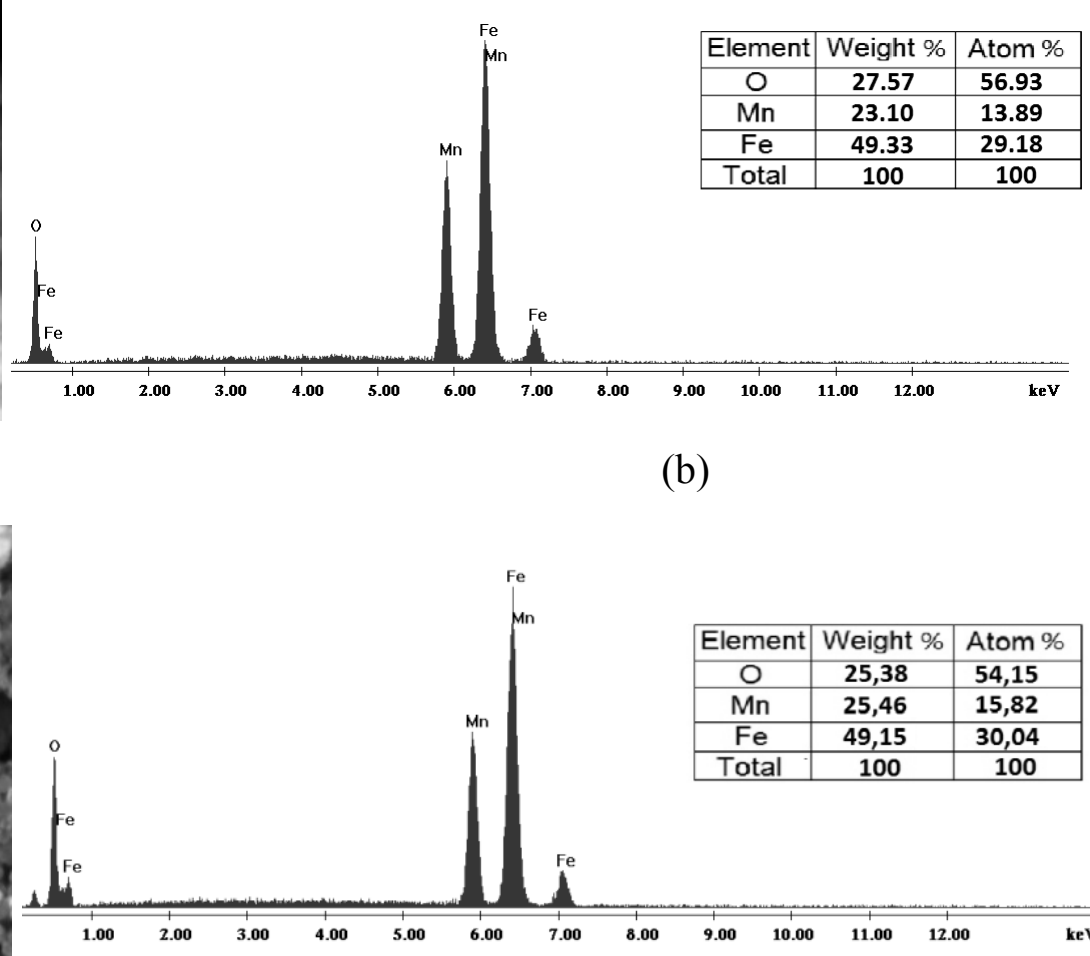

(b)

\begin{tabular}{|c|c|c|}
\hline Element & Weight \% & Atom \% \\
\hline $\mathrm{O}$ & $\mathbf{2 5 , 3 8}$ & $\mathbf{5 4 , 1 5}$ \\
\hline $\mathrm{Mn}$ & $\mathbf{2 5 , 4 6}$ & $\mathbf{1 5 , 8 2}$ \\
\hline $\mathrm{Fe}$ & $\mathbf{4 9 , 1 5}$ & $\mathbf{3 0 , 0 4}$ \\
\hline Total & 100 & 100 \\
\hline
\end{tabular}

(d)

Fig. 3. SEM morphology and EDX elemental analysis for samples: a) and b) for sample A along with c) and d) for sample B

\subsection{The impedance spectroscopy}

The frequency $(f)$ and temperature $(T)$ dependencies of the complex impedance, $Z(f, T)=Z^{\prime}(f, T)-i Z^{\prime \prime}(f, T)$ (where $i=\sqrt{-1}$ ), over the frequency range $20 H z$ to $2 M H z$ and at various values of temperature, within the range $30^{\circ} \mathrm{C}$ to $92^{\circ} \mathrm{C}$, were measured using an LCR meter (Agilent E4980A type). The ferrite samples were inserted into a furnace heated by means of electric resistors, connected to a source of voltage $u$. The sample was placed in a glass tube of length $L$ and section $A$, being in contact with two electrodes designed to press the sample and which allow the connection to the LCR meter. The furnace is thermally insulated and the temperature of the sample was measured using a thermocouple [8]. For a constant temperature $T$, the frequency dependence of real component $Z^{\prime}$ (resistance $R$ ) and imaginary component $Z^{\prime \prime}$ (reactance $-X$ ) of the sample were determined.

The complex impedance spectroscopy (CIS) is an important technique to study the electrical properties of the ferrites samples [9] in a wide range of frequencies and temperatures. This technique was among the most useful investigative techniques because the impedance of 
grains can be separated from the other impedance sources, namely the impedance of the electrodes and the impedance of grain boundaries [9, 10]. In this technique the imaginary component $Z^{\prime \prime}$ of the complex impedance $Z$ is plotted against the real component $Z$ ' of the complex impedance, thus obtaining the Nyquist diagram or the Cole-Cole arc (figure 4 a).

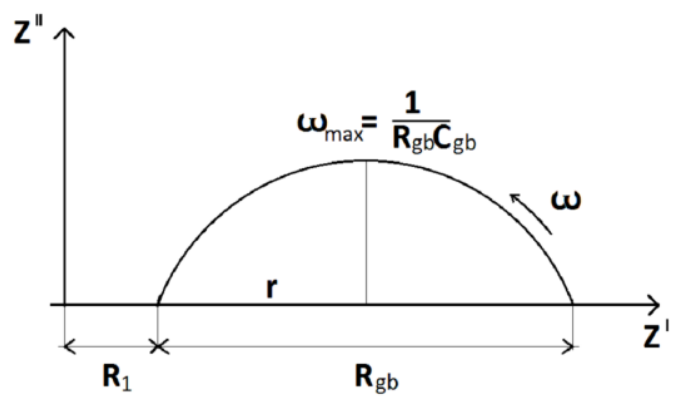

a)

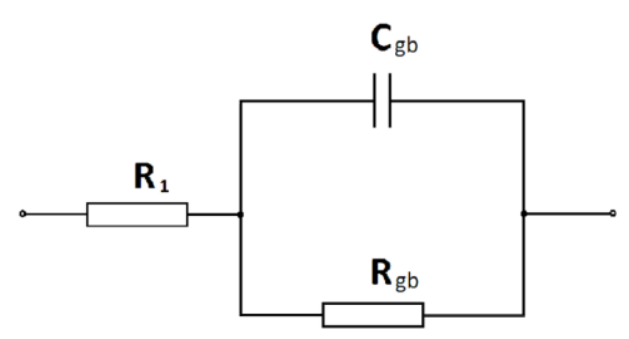

b)

Fig. 4. The Nyquist diagram (a) and the equivalent electrical circuit (b)

The impedance analysis of a granular material is based on an equivalent circuit (figure $4 \mathrm{~b}$ ) $[11,12]$ consisting of a resistance $R_{1}$ (due the contacts and electrical connections, which is very small in general), connected in series with a parallel combination of grain boundary resistance $\left(R_{g b}\right)$ and capacitance $\left(C_{g b}\right)$. For the equivalent circuit, the complex impedance is:

$$
Z=R_{1}+\frac{R_{g b}}{1-i \omega C_{g b} R_{g b}}=R_{1}+\frac{R_{g b}}{1+\omega^{2} C_{g b}^{2} R_{g b}^{2}}+i \frac{\omega C_{g b} R_{g b}^{2}}{1+\omega^{2} C_{g b}^{2} R_{g b}^{2}},(i=\sqrt{-1})
$$

From equation (1) one gets the real $\left(Z^{\prime}\right)$ and imaginary $\left(Z^{\prime \prime}\right)$ components of the complex impedance:

$$
Z^{\prime}=R_{1}+\frac{R_{g b}}{1+\omega^{2} C_{g b}^{2} R_{g b}^{2}}, \quad Z^{\prime \prime}=\frac{\omega C_{g b} R_{g b}^{2}}{1+\omega^{2} C_{g b}^{2} R_{g b}^{2}}
$$

By eliminating the frequency $\omega$ in equations (2), gives:

$$
\left(Z^{\prime}-R_{1}-\frac{R_{g b}}{2}\right)^{2}+Z^{\prime \prime 2}=\left(\frac{R_{g b}}{2}\right)^{2}
$$


Equation (3) represents a circle in the plane $Z^{\prime \prime} O Z^{\prime}$ with its center in $C\left(R_{1}+\frac{R_{g b}}{2} ; 0\right)$ and radius $r=\frac{R_{g b}}{2}$ (see figure $\left.4 \mathrm{a}\right)$ ).

The experimental frequency dependencies of $Z^{\prime}$ and $Z^{\prime \prime}$ of samples $\mathrm{A}$ and $\mathrm{B}$, at all temperatures within the investigation range, are shown in Figure 5.

As shown in figure $5 \mathrm{a}$ ) and figure $5 \mathrm{~b}$ ), the real component $Z^{\prime}$ of the complex impedance decreases with increasing frequency and temperature, for both samples. As a result, the conductivity of the samples increases with increasing temperature and frequency [13]. Overlapping of the curves $Z^{\prime}(f, T)$ in the region of high frequencies for the investigated samples, is probably due to the release of space charges due to the reduction in the barrier properties of the material at room temperature and can be explained by the presence of space charge polarization $[13,14]$. The same behavior of $Z^{\prime}$ component at lower frequencies has been observed by other authors [15-17].

The frequency dependence of the imaginary component, $Z^{\prime \prime}(f)$ has a maximum at a frequency $f_{\max }$ at each constant temperature, $T$, for both samples (see figure $5 \mathrm{a}$ ) and b)). The maximum of the imaginary component moves toward higher frequencies with the increase in temperature, for both samples. The maximum of the imaginary component of the complex impedance of sample A was found at frequencies of tens of $\mathrm{kHz}$ whilst the maximum of the imaginary component of the complex impedance of sample B was found at values in order of hundreds of Hz. Also, as can be observed from figure 5, the values of $Z^{\prime}$ and $Z$ ' obtained for sample A are in order of $10^{3} \Omega$, whilst the $Z^{\prime}$ and $Z^{\prime \prime}$ values for sample B are much higher, in order of $10^{6} \Omega$. This may be due to different morphological structure of the samples as resulted from the XRD analysis (sample A has perovskite structure and sample B has spinel structure).
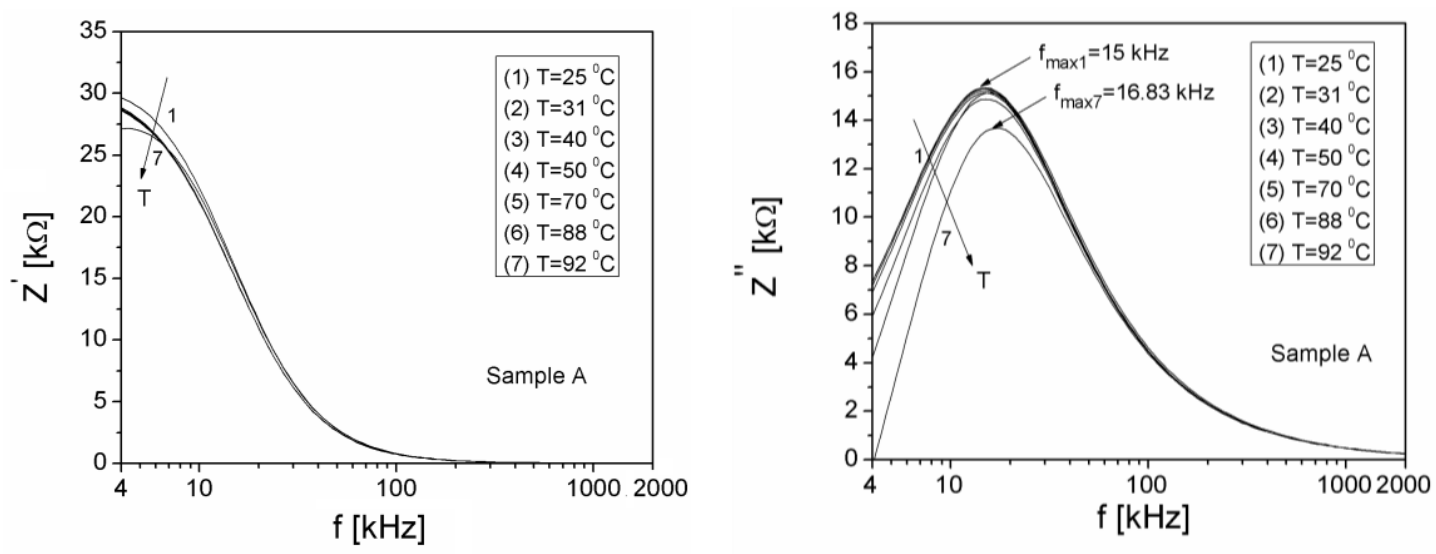

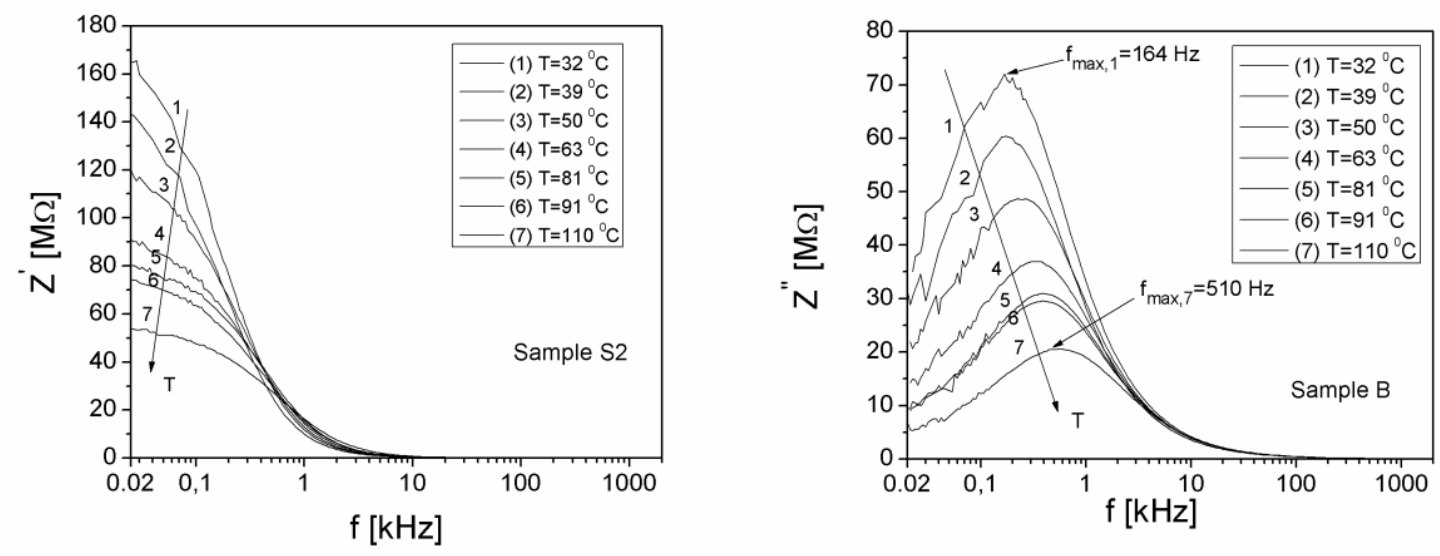

b)

Fig. 5. The frequency and temperature dependencies of real and imaginary components of the complex impedance of sample A (a) and sample B (b)

In Debye's theory [18] the frequency $f_{\max }$ indicating the maximum in the $Z$ ' $(f)$ dependence is correlated to the relaxation time $\tau$ by the equation:

$$
2 \pi f_{\max } \tau=1
$$

Using the experimental values of the $f_{\max }$ (see figure 5 a) and b)) and the equation (4), we have computed the relaxation time corresponding to each of the measurement temperature. The $f_{\max }$ and $\tau$ values obtained are listed in Table 3 for both samples.

Table 3. The $f_{\max }$ and $\tau$ values for both samples

\begin{tabular}{|c|c|c|c|}
\hline Samples & $\mathrm{T}[\mathrm{K}]$ & $\mathrm{f}_{\max }[\mathrm{kHz}]$ & $\tau[\mu \mathrm{s}]$ \\
\hline & 298 & 15.00 & 10.62 \\
& 304 & 15.20 & 10.48 \\
$\mathrm{~A}$ & 313 & 15.50 & 10.27 \\
& 323 & 15.65 & 10.17 \\
& 343 & 16.30 & 9.77 \\
& 361 & 16.71 & 9.53 \\
& 365 & 16.83 & 9.46 \\
\hline & 305 & 0.164 & 970.95 \\
& 312 & 0.185 & 860.73 \\
& 323 & 0.224 & 710.87 \\
& 336 & 0.280 & 568.7 \\
& 354 & 0.366 & 435.07 \\
& 364 & 0.404 & 394.15 \\
& 383 & 0.510 & 312.22 \\
\hline
\end{tabular}


In figure 6 we presented the variation of $\ln (\tau)$ versus 1000/T. It is observed that the value of $\tau$ decreases with the rise in temperature, which suggests a thermally activated process $[12,13]$. The temperature dependence of the relaxation time is of Arrhenius type, given by the equation:

$$
\tau=\tau_{0} \exp \left(\frac{E_{a}}{k T}\right)
$$

where $E_{a}$ is the activation energy and $\tau_{0}$ is a constant, which depends on the structure of material [9].
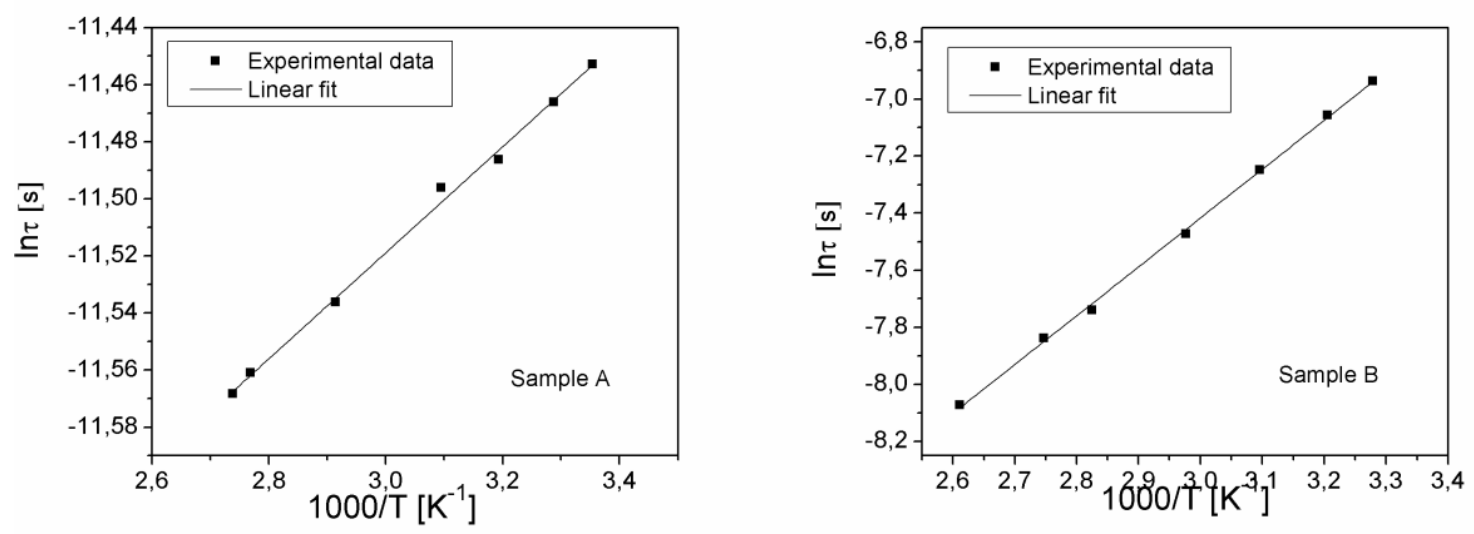

Fig. 6. Variation of $\ln (\tau)$ as a function of $(1000 / T)$

By fitting the temperature dependence of $\ln (\tau)$ from figure 5, to a linear equation, one obtains the parameters $E_{a}$ and $\tau_{0}$ corresponding to samples $\mathrm{A}$ and $\mathrm{B}$. The values obtained are: $E_{a}=16 \mathrm{meV}$ and $\tau_{0}=5.7 \cdot 10^{-6} \mathrm{~s}$ (for sample A) along with $E_{a}=147.65 \mathrm{meV}$ and $\tau_{0}=3.54 \cdot 10^{-6} s$ (for sample B), being in agreement with those obtained by other authors [12, 18]. The values obtained for the activation energy $E a$, show that the relaxation process and electrical conductivity are due to the grain boundary effect $[12,13,19]$.

The imaginary component $Z$ " of complex impedance versus the real component $Z$ ' (i.e. the Nyquist plot) has been plotted over a wide range of frequency and at different temperatures as presented in figure 7. 

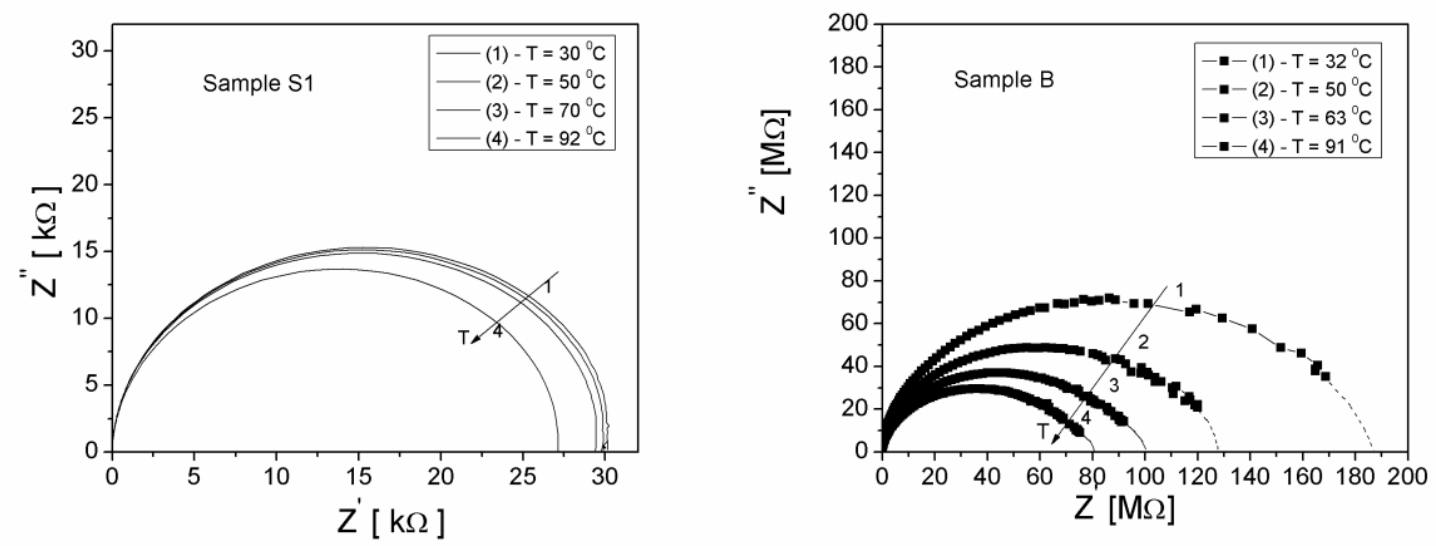

Fig. 7. The experimental Nyquist plots of sample A (a) and sample B (b)

As can be observed in figure 7, the impedance spectrum is characterized by the appearance of semicircular arcs. The diameter of semicircle decreases with the increase in temperature, denoting an increase of the DC conduction [12]. The appearance of a single semicircle at all temperatures means that the electrical process obeys a single relaxation mechanism [13]. The electrical processes occurring within the sample are correlated to the sample microstructure when it is modeled in terms of an electrical equivalent circuit $[12,20]$. In the case of samples A and B, the electrical equivalent circuit is similar with the circuit from figure $4 \mathrm{~b}$ ). The diameter of semicircle corresponds to the resistance of the grain boundary $R_{g b}$ [11-13] and the capacitance $C_{g b}$ is calculated from the frequency of semicircle maximum. By fitting the experimental data from figure 7 with the circle equation (3), we have determined the parameters $R_{1}, R_{g b}$ and $C_{g b}$ corresponding to each constant temperature $\mathrm{T}$, for both samples. The obtained values are listed in table 4 .

Table 4. The impedance parameters of samples at different temperatures.

\begin{tabular}{|c|c|c|c|}
\hline & $\mathrm{R}_{1}[\Omega]$ & $\mathrm{R}_{\mathrm{gb}}[\mathrm{k} \Omega]$ & $\mathrm{C}_{\mathrm{gb}}[\mathrm{pF}]$ \\
\hline$\underline{\text { Sample A }}$ & & & \\
$\mathrm{T}_{1}=304 \mathrm{~K}$ & 15.6 & 30.014 & 349.04 \\
$\mathrm{~T}_{2}=323 \mathrm{~K}$ & 11.5 & 29.398 & 346.10 \\
$\mathrm{~T}_{3}=343 \mathrm{~K}$ & 10.8 & 28.889 & 338.20 \\
$\mathrm{~T}_{4}=365 \mathrm{~K}$ & 10 & 28.390 & 333.30 \\
\hline$\underline{\text { Sample B }}$ & & & \\
$\mathrm{T}_{1}=305 \mathrm{~K}$ & 200 & 155,800 & 6.23 \\
\hline
\end{tabular}




\begin{tabular}{|c|c|c|c|}
\hline $\mathrm{T}_{2}=323 \mathrm{~K}$ & 1500 & 124,500 & 5.71 \\
$\mathrm{~T}_{3}=336 \mathrm{~K}$ & 1200 & 101,200 & 5.62 \\
$\mathrm{~T}_{4}=364 \mathrm{~K}$ & 1100 & 82,900 & 4.92 \\
\hline
\end{tabular}

In Table 4 the grain boundaries resistance $R_{g b}$, and the capacitance $C_{g b}$ of the samples A and $\mathrm{B}$, decreases with the increase of measurement temperature, indicating a lower barrier to the motion of charge carriers, increasing thus the electrical conductivity. This behaviour is similar to a semiconductor [13]. Therefore, the analysis of complex impedance data suggests that the capacitive and the resistive properties of the investigated samples are mainly determined by the conduction and relaxation processes associated with the grain boundaries effect.

\section{Conclusions}

The paper presents two methods for obtaining manganese ferrites powders, i.e. the calcination method at $700{ }^{\circ} \mathrm{C}$ (for sample A) and the hydrothermal method (for sample B). The nature of the crystalline phase of samples was examined using X-ray diffraction and the surface morphology study was performed by scanning electron microscopy (SEM).

The XRD pattern shows that the crystalline structure of samples is of perowskite type for sample $A$ and of spinel type for sample $B$. The sample $A$ has three phases $\left(\mathrm{Mn}_{2} \mathrm{O}_{3}, \mathrm{Fe}_{2} \mathrm{O}_{3}\right.$ and $\mathrm{FeMnO}_{3}$ as prevalent phase), whilst sample $\mathrm{B}$ has a single phase $\left(\mathrm{MnFe}_{2} \mathrm{O}_{4}\right)$. The average size of crystallites is $52.3 \mathrm{~nm}$ (for prevalent phase in sample A) and $31.9 \mathrm{~nm}$ (for sample B).

From the complex impedance measurements, $Z(f, T)=Z^{\prime}(f, T)-i Z^{\prime \prime}(f, T)$, over the frequency range $20 \mathrm{~Hz}-2 \mathrm{MHz}$, at various temperatures from $30^{\circ} \mathrm{C}$ to $100^{\circ} \mathrm{C}$, we have determined the temperature dependence of the relaxation time $\tau$ of the samples (which is the Arhenius type).

The results show that the relaxation time $\tau$ decreases with the temperature increasing, which suggests a thermally activated process. The values obtained for the activation energy $E a$, are: $E_{a}=16 \mathrm{meV}$ (for sample A) and $E_{a}=147.65 \mathrm{meV}$ (for sample B).

The analysis of complex impedance spectroscopy of the samples has shown the form of a single semicircle at all temperatures, meaning that the electrical process is characterized by a single relaxation mechanism. The electrical processes occurring within the sample are correlated to the sample microstructure when it is modeled in terms of an electrical equivalent circuit 
consisting of a resistance $R_{l}$ series with a parallel combination of resistance $R_{g b}$ and capacitance $C_{g b}$ of the grain boundary.

The results reveal that the capacitive and resistive properties of the investigated samples are determined by the grain boundaries in conjunction with the conduction and relaxation processes within the grains.

\section{Acknowledgments}

This work was supported by the strategic grant POSDRU/159/1.5/S/137750, Project "Doctoral and Postdoctoral programs support for increased competitiveness in Exact Sciences research" cofinanced by the European Social Found within the Sectorial Operational Program Human Resources Development 2007 - 2013.

\section{References}

[1] E. C. Snelling (editor), Soft Ferrites. Properties and Applications, $2^{\text {nd }}$ (1988) London: Butterworth

[2] S. Sam and A. S. Nesaraj, Int. J. Appl. Sci. Eng., 223 (2011) 223-239

[3] M.A.Ahmed, N.Okasha, S. I. El-Dek, Nanotechnology, 19 (2008) 065-603;

[4] Han Aijun, Liao Juanjuan, Ye Mingquan, Li Yan and Peng Xinhua, Chinese Journal of Chemical Engineering, 19(6) (2011) 1047-1051;

[5] Y.M.Z. Ahmed, Ceramics International, 36 (2010) 969-977

[6] M.M. Rashad, Materials Science \& Engineering B, 127, 2-3 (2006) 123-129|

[7] S.P. Yadav, S.S. Shinde, A.A. Kadam, K.Y. Rajpure, Journal of Alloys and Compounds, 555 (2013) 330-334

[8] A. Lungu, I. Malaescu, C. N. Marin, P. Vlazan, P. Sfirloaga, Physica B: Condensed Matter, 462 (2015) 80-85.

[9] J. T. S. Irvine, D. C. Sinclair, A. R. West, Adv. Mater., 2-3 (2004)132-138

[10] Khalid Mujasam Batoo, Physica B, 406 (2011) 382-387

[11] Khalid Mujasam Batoo, Shalendra Kumar, Chan Gyan Lee, Alimuddin, Journal of Alloys and Compounds, 480 (2009) 596-602.

[12] M. H. Abdullah, A. N. Yusoff, Journal of Materials Science, 32 (1997) 5817Đ5823

[13] S. Khadhraoui, A.Triki, S.Hcini, S.Zemni, M.Oumezzine, Journal of Magnetism and Magnetic Materials, 371(2014) 69-76 
[14] Khalid Mujasam Batoo, Shalendra Kumar, Chan Gyu Lee, Alimuddin, Current Applied Physics, 9 (2009) 1397-1406

[15] J. Plocharski, W.Wieczorek, Solid State Ion. 28-30 (1988)979.

[16] M. M. Costa, G. F. M. Pires Jr., A. S. B. Sombra, J. Mater. Chem. Phys,. 123 (2010) 35.

[17] J. Hu, H. Qin, J. Magn. Magn. Mater., 231(2001)L1.

[18] B. K. P. Scaife, Principles of dielectrics, Clarendon Press - Oxford, 1998

[19] D. K. Pradhan, B. K. Samantary, R. N. P. Chaudhary, A. K. Thakur, Mater. Sci. Eng. B $116(2005) 7$.

[20] H. F. Cheng, J. Appl. Phys., 56 (1984) 1831-1837. 